\title{
KEARIFAN LOKAL PENGGUNAAN KAYU GELAM DALAM TANAH RAWA GAMBUT DI KALIMANTAN TENGAH \\ (Local Wisdom of Utilization of Gelam Wood on Peatswamp Land of Central Kalimantan)
}

\author{
Wahyu Supriyati ${ }^{1, *}$, Tibertius Agus Prayitno ${ }^{2}$, Sumardi $^{2}$ dan Sri Nugroho Marsoem² \\ ${ }^{1}$ Jurusan Kehutanan, Fakultas Pertanian, Universitas Palangka Raya, \\ Jalan Yos Sudarso, Kampus Unpar Tunjung Nyaho, Palangka Raya 73111. \\ ${ }^{2}$ Fakultas Kehutanan, Universitas Gadjah Mada, Bulaksumur Yogyakarta 55281. \\ *Penulis korespondensi. No telp:0536-3224104. Email: wahyu_plk@yahoo.com.
}

Diterima: 13 Agustus 2014

Disetujui: 23 Februari 2015

\begin{abstract}
Abstrak
Masyarakat di daerah rawa gambut memerlukan kayu sebagai cerucuk atau tiang pancang rumah. Kayu gelam (Maleleuca sp) ditemukan melimpah di hutan rawa gambut di Kalimantan. Kayu gelam termasuk kelas awet 3 yang berarti hanya dapat dipergunakan bila berhubungan dengan tanah selama 3 tahun. Kenyataan yang ada kayu gelam sebagai cerucuk /tiang pancang rumah dalam tanah rawa tetap kuat selama lebih dari 30 tahun. Pemanfaatan kayu ini mendukung untuk konservasi hutan rawa gambut. Tujuan dari penelitian ini adalah untuk mempelajari pengaruh lama penimbunan dan letak radial terhadap sifat fisika, mekanika dan kandungan silika kayu gelam. Penelitian dilakukan pada kayu gelam yang telah ditimbun dalam rawa gambut selama 10, 19, 31 dan 38 tahun. Sifat kayu yang dianalisis adalah sifat fisika mekanika mengikuti BS No 373. Uji silika dengan spektrometer. Analisis menggunakan rancangan acak lengkap dengan faktorial. Hasil menunjukkan bahwa lama penimbunan meningkatkan berat jenis kayu gelam secara signifikan. Semakin lama penimbunan, semakin tinggi berat jenis (0,54-0,75). Persamaan yang diperoleh $\mathrm{Y}=0,449+0,063 \mathrm{x}_{1}+0,01 \mathrm{x}_{2}\left(\mathrm{Y}=\mathrm{BJ}\right.$ kering tanur, $\mathrm{x}_{1}=$ lama penimbunan, $\mathrm{x}_{2}=$ letak radial). Pengaruh lama penimbunan pada kekerasan sejalan dengan BJ. Kadar silika kayu Gelam meningkat dengan semakin lama penimbunan. Lama penimbunan (10-38 tahun) meningkatkan BJ kering tanur 28,13 \%, kekerasan 12,83\%; kandungan silika 1,25\%. Penggunaan kayu gelam merupakan kearifan lokal yang terbukti melestarikan lingkungan karena menghemat pemanfaatan kayu yang dinyatakan dengan kualitas kayu gelam yang relatif tidak menurun dalam penimbunan.
\end{abstract}

Kata kunci: kayu gelam, kearifan lokal, lama penimbunan, rawa gambut, sifat fisika-mekanika, silika.

\begin{abstract}
Local community on peatswamp area need woods as poles. Gelam (Maleleuca sp) wood is found abundantly in peatswamp forest area in Kalimantan. It is 3th durability class and expected to withstand up to three years of utilitation outdoor. However, gelam wood used for house poles in peatswamp could be still strong enough more than 30 years. Utilization this wood supports to conservation of peatswamp forest. The aim of this research is to study the effect of burying time and radial position to physical, mechanical properties and silica content of gelam The research was conducted by gelam wood which buried in peatswamp for several years namely 10, 19, 31 and 38 years. Wood properties that analyzed were physical and mechanical properties followed the British Standard No. 373. Silica testing by spectrometer. Analyze use factorial experimental of Completely Random Design. The result showed that wood specific gravity significantly increase with the lenght of burying time. The longer burying time, the higher wood specific gravity (0.54 to 0.75). Equation $Y=0.449+0.063 x_{1}+0.01 x_{2}$ ( $Y=$ oven dry $S G, x_{1}=$ burying time, $x_{2}=$ radial posision). The effect of burying time on hardness parallel with wood specific gravity. Burying time factor increase value of specific gravity $28.13 \%$, hardness $12.83 \%$; silica content $1.25 \%$. The use of gelam wood support to conserve the environment because it saves wood utilization expressed by gelam wood quality relatively undegradation in burial.
\end{abstract}

Keywords: gelam wood, local wisdom, burying time, peatswamp, physical-mechanical properties, silica content.

\section{PENDAHULUAN}

Masyarakat di Kabupaten Kapuas Barat, Kalimantan Tengah hidup di daerah tanah rawa gambut. Tanah ini kurang stabil dalam penggunaan sebagai lahan pembangunan rumah dan jalan raya. Penggunaan cerucuk sebagai pondasi dalam tanah rawa gambut menjadi hal yang umum. Kebutuhan masyarakat akan kayu sebagai cerucuk telah mengantarkan penggunaan gelam (Maleleuca sp).
Kearifan lokal ini telah menjadi fenomena menarik di daerah tanah rawa gambut.

Kayu gelam ditemukan melimpah di hutan rawa gambut di Kalimantan Tengah, Kalimantan Selatan dan pesisir Sumatera Selatan. Kayu gelam termasuk kelas awet 3 yang berarti hanya dapat dipergunakan di atas tanah selama 3 tahun (Anonim, 1976). Kenyataan yang ada masyarakat menggunakan kayu gelam sebagai cerucuk (tiang 
pancang atau pondasi dalam tanah) selama lebih dari 30 tahun.

Penggunaan kayu sebagai cerucuk / tiang pancang/pondasi dalam tanah rawa oleh masyarakat memerlukan kayu yang kuat dan awet. Cerucuk adalah sistem pondasi rumah di tanah rawa. Cerucuk terdiri atas kayu gelam berbaring dan berdiri dan ditimbun dalam tanah rawa. Kualitas kayu adalah kesesuaian kayu dengan tujuan penggunaannya. Fakta dalam masyarakat membuktikan cerucuk gelam dipakai untuk masa pakai yang lama. Penggunaan kayu gelam ini mendukung pelestarian lingkungan yaitu menghemat menggunaan kayu sebagai cerucuk. Hal ini sejalan dengan temuan Mulyadi (2011) yang juga menemukan kearifan lokal yang berwawasan lingkungan di Soppeng.

Kualitas kayu ditentukan oleh faktor di dalam kayu dan faktor di luar kayu. Faktor di dalam kayu antara lain adalah posisi dalam batang. Faktor di luar kayu terdiri atas kondisi lingkungan penggunaan kayu dalam hal ini adalah faktor abiotik (oksidasi, foto oksidasi, ph air/tanah rawa) dan faktor biotik (jamur, serangga perusak kayu). Pengaruh faktor dalam kayu dan faktor di luar kayu terhadap kayu menunjukkan tingkat kualitas kayu.

Tujuan penelitian ini adalah untuk mengetahui pengaruh lama penimbunan dan letak pada arah radial dan interaksi kedua faktor itu terhadap perubahan sifat fisika-mekanika kayu dan kandungan silika kayu gelam yang telah ditimbun dalam tanah rawa selama 10, 19, 31 dan 38 tahun.

\section{METODE PENELITIAN}

\section{Waktu dan Lokasi}

Penelitian dilaksanakan ini dilaksanakan selama 8 bulan yaitu dari bulan Juni 2009-Pebruari 2010. Semua kayu ini berasal dari Kabupaten Kapuas Barat Kalimantan Tengah. Kayu gelam dipilih secara acak dari cerucuk rumah penduduk yang telah ditimbun dalam tanah rawa selama 10, 19, 31 dan 38 tahun

\section{Bahan dan Alat}

Bahan yang digunakan dalam penelitian ini adalah batang gelam sebanyak 12 batang berdiameter $<10 \mathrm{~cm}$. Bahan uji silika meliputi amonium molibdat $\left(\mathrm{NH}_{4}\right)_{6} \mathrm{Mo}_{7} \mathrm{O}_{24} \cdot 4 \mathrm{H}_{2} \mathrm{O}, \mathrm{H}_{2} \mathrm{SO}_{4}$, asam tartrat $8 \%$, anhidrat natrium sulfit, 1-amino-2naftol-4-sulfonat, natrium bisulfit, $\mathrm{HCl}$, dan aquades. Peralatan uji fisika dan mekanika yang digunakan antara lain meteran, chainsaw, gergaji potong, mesin uji universal (UTM), oven, timbangan, bejana kaca, dan statip. Peralatan uji silika adalah cawan nikel, oven pengabuan, pipet, dan alat spektrometer.

\section{Prosedur Kerja}

Pembuatan contoh uji dan pengujian mengacu pada British Standard No. 373 (Anonim, 1957) seperti disajikan pada Gambar 1. Pengujian mekanika kayu dilakukan pada kondisi kering udara. Pengujian contoh uji sifat fisika kayu berupa berat jenis (BJ) berdasarkan volume basah, kering udara dan kering tanur (BJKT).

Pengujian contoh uji sifat mekanik kayu berupa kekerasan dan keteguhan lengkung statik meliputi : tegangan pada batas proporsi (BP), keteguhan patah / Modulus of Rupture (MOR) dan keteguhan elastisitas / Modulus of Elasticity (MOE). Pelaksanaan uji silika mengacu pada modifikasi Priyana dkk (1979). Perhitungan dilakukan sesuai Tabel 1.

\section{HASIL DAN PEMBAHASAN}

Penggunaan kayu sebagai cerucuk dengan masa pakai yang lama sangat dibutuhkan di tanah rawa. Sifat kayu yang dingini diharapkan tidak berubah dalam penggunaan di dalam tanah yang memiliki $\mathrm{pH}$ rendah (asam).

Kayu gelam telah digunakan sebagai cerucuk oleh masyarakat di daerah rawa gambut sejak zaman dulu sebagai suatu kearifan lokal. Saat ini masyarakat tetap memiliki kecenderungan menggunakannya. Hal ini didorong kemampuan kayu gelam yang merupakan tumbuhan pionir di areal bekas terbakar dan toleran pada daerah tergenang yang membuatnya relative mudah tersedia. Penggunaan kayu gelam sebagai cerucuk di tanah rawa mendorong penghematan penggunaan kayu yang ditunjukkan dengan hasil sifat dasar kayu yang diteliti yang menunjukkan sifatnya yang tidak terdegradasi.

\section{Sifat Fisika Kayu}

Pola perubahan BJ akibat faktor lama penimbunan dan letak radial batang disajikan dalam

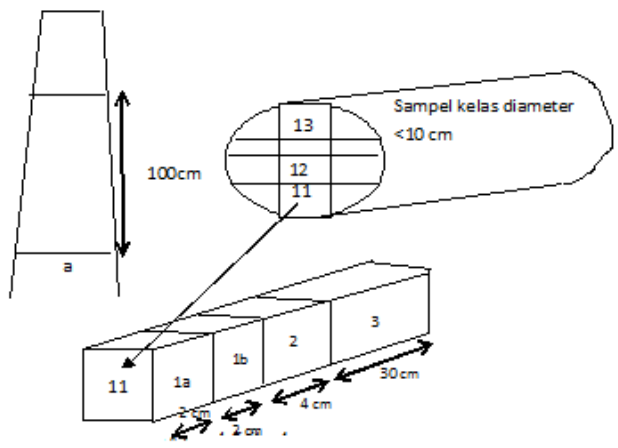

Gambar 1. Pengambilan sampel fisika dan mekanika kayu gelam. Keterangan : $\mathrm{a}=$ bagian pangkal batang gelam ; 1a,1b = sampel kadar air/berat jenis ; $2=$ sampel kekerasan ; $3=$ sampel keteguhan lengkung statik; $12=$ dekat hati, 11, 13=dekat kulit. 
Tabel 1. Rumus perhitungan parameter fisika mekanika dan silika.

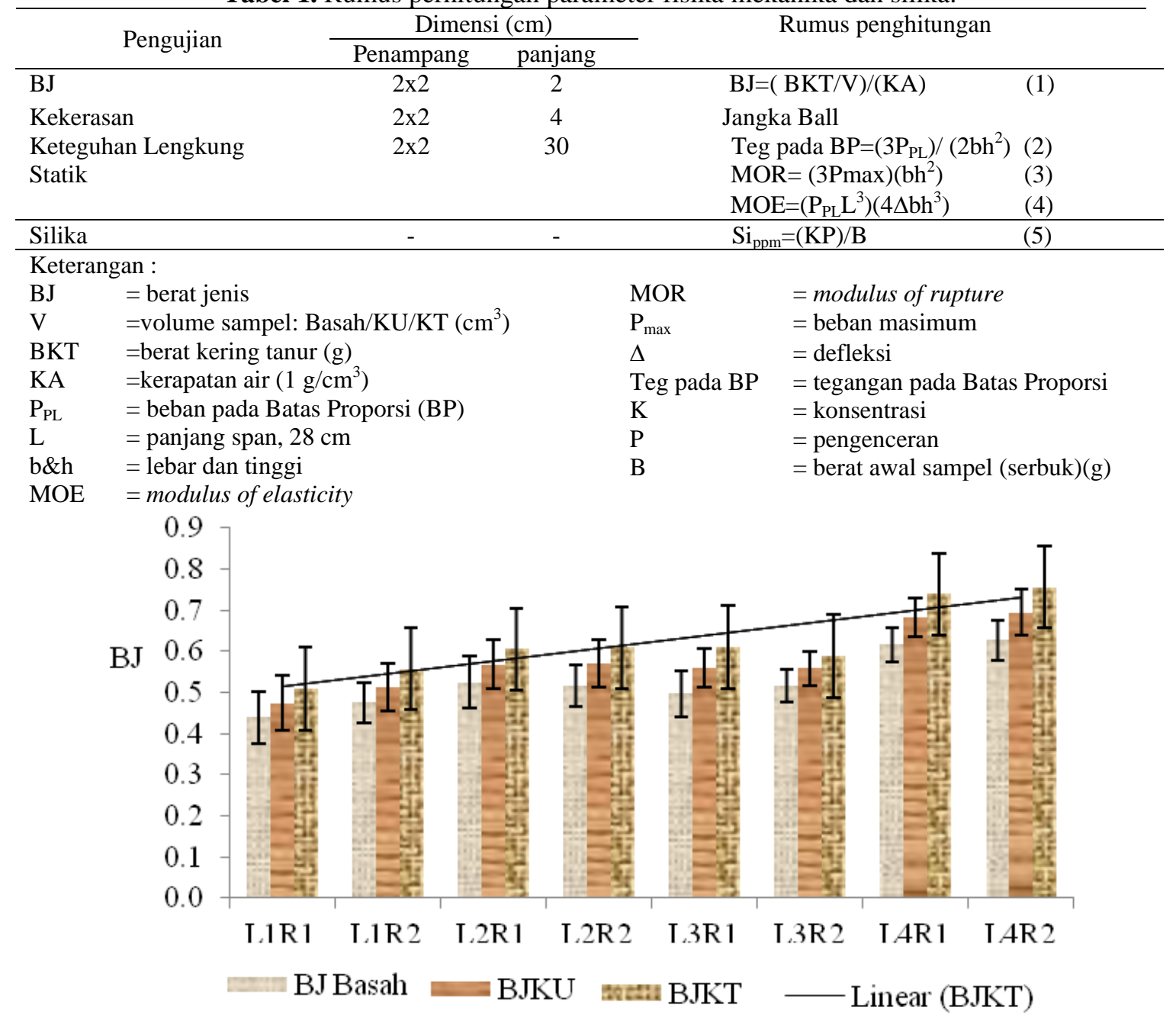

Gambar 2. Pengaruh kombinasi perlakuan terhadap berat jenis kayu gelam. Keterangan $\mathrm{L}=\mathrm{lama}$ ( $1=10$ tahun, 2=19 tahun, 3=31 tahun, 4=38 tahun), R=letak radial (1=dekat hati, 2- dekat kulit).

Tabel 2. Ringkasan analisis varian pengaruh lama penimbunan dan letak pada arah radial terhadap parameter uji sifat fisika.

\begin{tabular}{lrccc}
\hline \multicolumn{1}{c}{ Faktor } & df & BJ Basah & BJKU & BJKT \\
\hline Lama & 3 & $27,98^{* *}$ & $33,62^{* *}$ & $36,75^{* *}$ \\
Radial & 1 & $1,09 \mathrm{~ns}$ & $0,74 \mathrm{~ns}$ & $0,59 \mathrm{~ns}$ \\
Lama x radial & 3 & $0,45 \mathrm{~ns}$ & $0,37 \mathrm{~ns}$ & $0,95 \mathrm{~ns}$ \\
\hline
\end{tabular}

\begin{tabular}{llll}
\hline Jumlah sampel & 60 & 60 & 60
\end{tabular}

Keterangan : **=berbeda sangat signifikan, ns= tidak signifikan, $\mathrm{n}=$ jumlah sampel.

Tabel 3. Uji beda pengaruh lama penimbunan terhadap parameter uji sifat fisika.

\begin{tabular}{lllll}
\hline \multicolumn{1}{c}{ Parameter } & \multicolumn{3}{c}{ Uji beda 5\% } \\
\hline BJ Basah & L1a & L3a & L2a & L4b \\
BJKU & L1a & L3b & L2b & L4c \\
BJKT & L1a & L3b & L2b & L4c \\
\hline
\end{tabular}

Keterangan : huruf yang sama menyatakan antara tingkat perlakuan tersebut "tidak berbeda signifikan"; Nilai diurutkan dari yang terkecil ke yang terbesar. bentuk grafis pada Gambar 2. Ringkasan uji statitik ditampilkan pada Tabel 2. Uji beda diperlihatkan Tabel 3.

Uji statistik dan uji beda HSD (Tukey) signifikansi 95\% pada nilai berat jenis (BJ) kayu 38 tahun secara signifikan berbeda (lebih tinggi) dibandingkan kayu yang lain. Perendaman dan kondisi di bawah tanah menjadi awal proses yang sangat lambat dari fosilisasi di mana substansi dinding sel berubah menjadi senyawa yang memadat (coalification) atau digantikan oleh mineral (silisifikasi).

Tabel 4 menunjukkan persamaan regresi yang diperoleh dari hubungan sifat fisika dengan lama penimbunan dan letak radial. Koefisien korelasi (R) antara BJKT dan faktor lama-radial adalah 0,739. Hal ini berarti hubungan antara BJKT dengan lama penimbunan dan letak radial adalah sebesar 73,39 $\%$. Koefisien determinasi $\left(\mathrm{R}^{2}\right)$ BJKT menunjukkan bahwa $54,6 \%$ variasi yang terjadi terhadap BJKT 
Tabel 4. Persamaan regresi, koefisien korelasi (R) dan koefisien determinasi sifat fisika.

\begin{tabular}{llcc}
\hline Y (Sifat) & \multicolumn{1}{c}{ Persamaan } & $\mathrm{R}$ & $\mathrm{R}^{2}$ \\
\hline BJBasah & $\mathrm{Y}=0,388+0,047 \mathrm{X}_{1}+0.013 \mathrm{X}_{2}$ & 0,709 & 0,502 \\
BJKU & $\mathrm{Y}=0,0418+0,057 \mathrm{X}_{1}+0,011 \mathrm{X}_{2}$ & 0,743 & 0,552 \\
BJKT & $\mathrm{Y}=0,449+0,063 \mathrm{X}_{1}+0,01 \mathrm{X}_{2}$ & 0,739 & 0,546 \\
\hline
\end{tabular}

Keterangan : $\mathrm{X}_{1}=$ lama penimbunan; $\mathrm{X}_{2}=$ letak radial

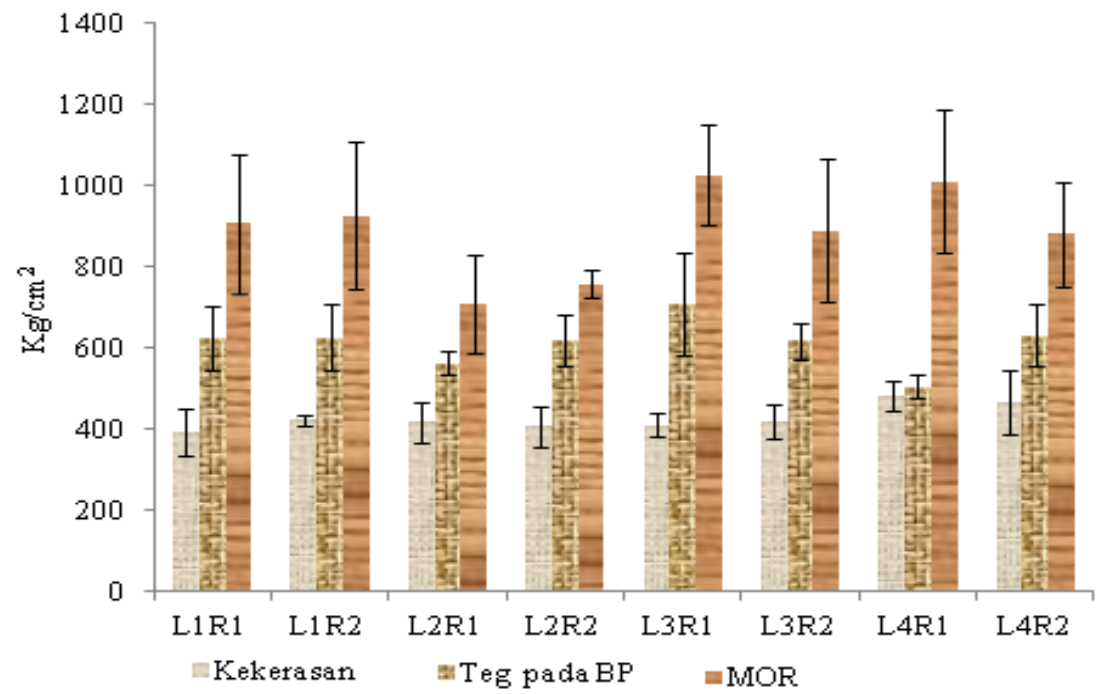

Gambar 3. Pengaruh kombinasi perlakuan terhadap sifat mekanika kayu gelam. Keterangan $\mathrm{L}=\mathrm{lama}(1=10$ tahun, 2=19 tahun, 3=31 tahun, 4=38 tahun), $\mathrm{R}=$ letak radial (1=dekat hati, 2- dekat kulit).

disebabkan variasi lama penimbunan dan letak radial.

Interaksi lama tertimbun dan letak radial pada sifat fisika secara statistik tidak berbeda signifikan. Interaksi faktor dengan nilai BJKT tertinggi ditemukan ada kombinasi L4R2 (lama 38 tahun, dekat kulit). Penimbunan telah meningkatkan berat jenis kayu gelam. BJKT pada lama penimbunan 1038 tahun masing-masing adalah 0,54, 0,60, 0,61 dan 0,75. Terjadi peningkatan sebesar 28,13\% pada penimbunan 38 tahun dibandingkan penimbunan 10 tahun. Peningkatan ini diduga akibat infiltrasi zat-zat dalam medium penimbunan tanah rawa yang cenderung basah seperti dalam penelitian Akahane yang meningkat akibat penimbunan dalam air (Akahane dkk, 2004). Menurut Jordan dkk (2010) kondisi terkubur membusuk lebih lambat daripada kayu yang diekspos. Pengunaan kayu gelam sebagai cerucuk dalam tanah rawa gambut ini mendukung upaya pelestarian hutan rawa gambut melalui pengghematan penggunaan kayu.

Berat jenis menunjukkan ukuran kandungan kayu. Christienin dkk (2009) menyatakan bahwa jika pohon dibenamkan dalam air atau tanah, fosilisasi dimulai tanpa oksigen, yang pada akhirnya akan menyebabkan karbonisasi atau membatu (petrifikasi) tergantung pada kondisi pembenaman di dalam lingkungan anaerobik ini.

\section{Sifat Mekanika Kayu}

Pola kekerasan serupa dengan pola BJ, yaitu semakin lama ditimbun semakin keras (Gambar 3). Peningkatan kekerasan seiring lama penimbunan tetapi secara statistik tidak signifikan. Peningkatan kekerasan L10-L38 adalah sebesar 12,83\%. Peningkatan BJ cenderung meningkatkan kekerasan kayu, serupa dengan pendapat Pometti dkk. (2009) bahwa peningkatan BJ cenderung meningkatkan kekuatannya. Hal ini menjelaskan hubungan antara BJ dan sifat mekanika (Zang, 1996).

Lama penimbunan tidak berpengaruh signifikan pada seluruh sifat mekanikanya. Artinya, kemampuan mekanika kayu-kayu dalam variasi lama penimbunan 10-38 tahun tersebut tidak berbeda signifikan. Hal serupa ditemukan pada hasil penelitian Lionetto dkk (2014), yang juga hanya menemukan sedikit perubahan akibat penimbunan.

Proses dekomposisi adalah hasil dari interaksi yang kompleks antara lingkungan dan kayu itu sendiri. Penimbunan kayu gelam selama 10-38 tahun memberikan nilai mekanika yang tidak berbeda signifikan. Hal ini merupakan suatu kelebihan dalam kayu gelam dalam kemampuannya mempertahankan kualitas sifat mekanikanya sehingga pemanfaatan gelam dalam penimbunan sebagai cerucuk (tiang pancang) dapat direkomendasikan. Christienin dkk (2009) menyatakan bahwa karbonisasi atau petrifikasi 
Tabel 5. Ringkasan analisis varians pengaruh lama penimbunan dan letak radial terhadap sifat mekanika.

\begin{tabular}{lccccc}
\hline \multicolumn{1}{c}{ Faktor } & df & Kekerasan & Tegangan pada BP & MOR & MOE \\
\hline Lama & 3 & $2,97 \mathrm{~ns}$ & $2,38 \mathrm{~ns}$ & $3,02 \mathrm{~ns}$ & $0,94 \mathrm{~ns}$ \\
Radial & 1 & $0,02 \mathrm{~ns}$ & $0,74 \mathrm{~ns}$ & $0,77 \mathrm{~ns}$ & $0,11 \mathrm{~ns}$ \\
Lama * Radial & 3 & $0,27 \mathrm{~ns}$ & $3,04 \mathrm{~ns}$ & $0,72 \mathrm{~ns}$ & $0,50 \mathrm{~ns}$ \\
\hline Jumlah sampel & & 30 & 30 & 30 & 30 \\
\hline
\end{tabular}

Keterangan : **=berbeda sangat signifikan, ns= tidak signifikan

tergantung pada kondisi pembenaman di dalam lingkungan anaerobik ini.

Penimbunan kayu gelam sebagai cerucuk ini merupakan kearifan lokal berwawasan lingkungan yaitu menghemat penggunaan kayu karena kayu gelam memiliki masa pakai yang panjang sebagai cerucuk. Kearifan lokal berwawasan lingkungan juga ditemukan di Sopeng (Mulyadi, 2011).

\section{Kandungan Silika}

Kandungan silika tidak dipengaruhi oleh faktor lama penimbunan dan faktor letak radial ataupun interaksinya. Berdasarkan hasil penelitian, rata-rata kadar silika kayu gelam dalam penimbunan adalah sebesar 0,86 \%. Pada kayu tertimbun 10, 19, 31 dan 38 tahun kadar silika masing-masing 0,85 \%.0,86 $\% .0,85 \% .0,86 \%$. Ada kecenderungan peningkatan kadar silika, yaitu sebesar 1,25 \% pada kayu yang ditimbun 10 dibandingkan kayu yang ditimbun 38 tahun. Pada letak radial dekat hati dan dekat kulit masing masing adalah 0.85 dan 0,86 yang menunjukkan bahwa kehadiran silika lebih banyak pada daerah dekat kulit. Secara statistik tidak menunjukkan perbedaan yang signifikan di antara variasi lama penimbunan dan letak pada arah radial.

Kayu gelam setelah penimbunan menunjukkan perubahan fisik yang agak mengeras pada lama penimbunan 38 tahun. Menurut Weibel (1996) proses transformasi dari kayu (lignifikasi dan membatu) tergantung pada permeabilitas sedimen. Agen pembatuan (petrifying agent) di kayu adalah silika, yang berasal dari pelapukan mineral silikat menjadi sedimen.

Peningkatan silika dalam kayu ditunjukkan dengan persamaan linier berikut (Gambar 4). Koefisien determinasi $\left(\mathrm{R}^{2}\right)$ menunjukkan bahwa $61,3 \%$ variasi yang terjadi terhadap kadar silika disebabkan variasi lama penimbunan. Hal ini sejalan dengan pernyataan Viney (2011) bahwa mineralisasi fosil terbentuk ketika larutan yang kaya akan mineral menembus jaringan berpori, seperti kayu. Mineral mengendap dari larutan kaya mineral dan mengisi pori-pori dan ruang kosong. Dalam kasus kayu, petrifikasi/pembatuan terjadi ketika selulosa, hemiselulosa dan lignin dalam dinding sel dari jaringan kayu bertindak sebagai kerangka untuk keawetan.

Peningkatan silika pada kayu gelam dalam periode 10-38 tahun (periode 28 tahun) adalah

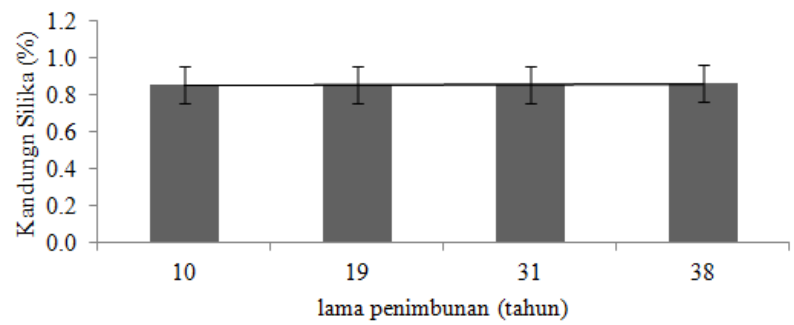

Gambar 4. Kadar silika (\%) dalam lama penimbunan (10-38 tahun).

sebesar 1,25\%. Asam silika amorf dan kristalin dapat menyebabkan silisifikasi. Kristalinitas mungkin muncul selama atau setelah penetrasi ke dalam kayu. Penelitian Akahane dkk (2004) dalam hot spring water (air panas musim semi) menemukan bahwa perubahan bagian kayu mencapai $40 \%$ beratnya pada periode 7 tahun.

Berdasarkan hasil penelitian ini, kearifan lokal dalam penggunaan cerucuk kayu gelam sebagai pondasi dalam tanah rawa gambut yang selama ini ternyata memang didukung oleh sifat kayu gelam. Kayu gelam memiliki kemampuan mempertahankan dirinya dari degradasi dalam kondisi tertimbun. Hal ini dapat memperpanjang masa pakai kayu yang berdampak pada penghematan penggunaan kayu.

\section{KESIMPULAN}

Penimbunan telah meningkatkan berat jenis (BJ) kayu gelam secara signifikan. Sifat mekanika tidak dipengaruhi lama penimbunan, letak radial maupun interaksi kedua faktor Pola kekerasan serupa dengan pola BJ, yaitu semakin lama ditimbun semakin keras. Peningkatan kekerasan seiring lama penimbunan tetapi secara statistik tidak signifikan.

Kandungan silika tidak dipengaruhi lama penimbunan, letak radial maupun interaksi kedua faktor. Peningkatan silika terjadi seiring lama penimbunan tetapi tidak signifikan. Penggunaan kayu gelam sebagai cerucuk ini merupakan kearifan lokal yang berwawasan lingkungan yaitu menghemat menggunaan kayu sebagai cerucuk. Kayu gelam dalam penimbunan tidak mengalami degradasi. 


\section{DAFTAR PUSTAKA}

Akahane, H., Furuno, T., Miyajima, H., Yoshikawa, T., dan Yamamoto, S., 2004. Rapid Wood Silicification In Hot Spring Water: An Explanation of Silicification of Wood During The Earth's History. Sedimentary Geology, 169:219-228.

Anonim, 1957. Methods of Testing Small Clear Specimen of Timber. British Standard 373, London.

Anonim, 1976. Vademecum Kehutanan Indonesia. Departemen Pertanian Direktorat Jenderal Kehutanan, Jakarta, pp 5-66.

Christiernin, M., Notley, S.M., Zhang, L., Nilsson, T., dan Henriksson, G., 2009. Comparison Between 10,000-Year Old and Contemporary Spruce Lignin. J. Wood Sci. Technol., 43:2341.

Jordan, A., Cicale, M., Hofberg, M., Junghans, J., Kerrick, H., Luo, G., Mercado, M., Oliver, S., Neill, S.O'., Remer, D., Schulzinger,M., Shofnos, R., Tolley, H., dan Tse, W., 2010. The Effect of Wood Burial and Submersion on Decomposition: Implications for Reducing Carbon Emissions. Website : http://drum.lib. umd.edu/bitstream/1903/10081/1/CarbonSinks .pdf

Lionetto, F., Quarta, G., Cataldi, A., Cossa, A., Auriemma, R., Calcagnile, L., dan Frigione, M., 2014. Case Study: Characterization and Dating of Waterlogged Woods from An
Ancient Harbor in Italy. Journal of Cultural Heritage, 15(2):213-217.

Mulyadi, 2011. Pengaruh Kearifan Lokal, Locus Of Control dan Motivasi Terhadap Perilaku Berwawasan Lingkungan Petani dalam Mengelola Lahan Pertanian Di Kabupaten Soppeng. Jurnal Manusia dan Lingkungan, 18(1):60-67.

Pometti, C.L., Pizzo, B., Brunetti,M., Macchioni, N., Ewens, M., dan Saidman, B.O., 2009. Argentinean Native Wood Species: Physical and Mechanical Characterization of Some Prosopis Species and Acacia Aroma (Leguminosae; Mimosoideae). Bioresource Technology, 100:1999-2004.

Priyana, Mudjiran, Narsito, dan Akhmad. S., 1979. Analisa Kimia Unsur-unsur Utama dalam Bahan-bahan Bumi. Fakultas Ilmu Pasti dan Alam. UGM. Yogyakarta.

Viney, M., 2011. Petrified Wood: The Silicification of Wood by Permineralization. Diakses dari http://petrifiedwoodmuseum.org/PDF/Permine ralization.pdf.

Weibel, R., 1996. Petrified Wood from An Unconsolidated Sediment, Voervadsbro, Denmark. Sedimentary Geology, 101(1-2):3141.

Zhang, S.Y., 1996. The Wood Specific GravityMechanical Property Relationship at Species Level. J. Wood Sci. Technol., 31:181-191. 